\title{
Maximum Continuous Operation Time Control of PMSM with Compressor Loads of Air Conditioners under DC Power Supply Loss
}

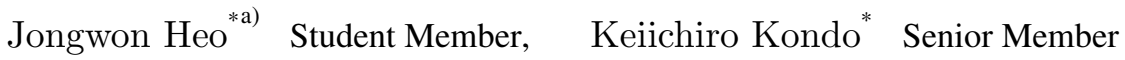 \\ (Manuscript received Jan. 12, 2018, revised Feb. 6, 2018)
}

In this letter, a method to maximize the operation time, even in cases of longer power interruption, by minimizing the power lost by the load is developed using the Lagrange function.

Keywords: PMSM, power supply loss, continuous operation, low inertial loads

\section{Introduction}

The permanent magnet synchronous motors (PMSM) drive systems for the compressor of air conditioners are required to continue its operation as long as possible even when the input power source is interrupted. Because it takes long time to recover the heat cycle, once it stops. In the case of short time power interruption, a method to utilize both Filter Capacitor (FC) energy and kinetic energy was proposed to continue its operation until the power source is recover ${ }^{(1)}$. However, in the case of long time power interruption, it is preferable to continue the operation for as long as possible by minimizing the losses. In this letter, a method to maximize the operation time even in the case of the longer power interruption by minimizing the power lost by the load is derived by means of the Lagrange function.

\section{Modeling}

The modelling of the physical behavior including each loss is performed. The load torque of the compressor $\tau_{L}$ is assumed as constant regardless of the rotating speed. The load torque of the compressor is mainly determined by the conditions of discharge pressure and suction pressure of the compressor. Within a few seconds of an instantaneous power interruption, even if the rotating speed change, the discharge pressure and suction pressure do not change greatly unless the cycle conditions such as valve conditions change in the refrigerant cycle. And, d-axis current value $i_{d}$ is set to 0 .

When the power supply is interrupted, the overall energy $E_{\text {all }}$ coincides with the sum of the integral of the overall losses of the whole system $P_{\text {loss }}$ and the power transmitted from FC Energy and/or kinetic energy to the load side $P_{\text {load }}$ as follows:

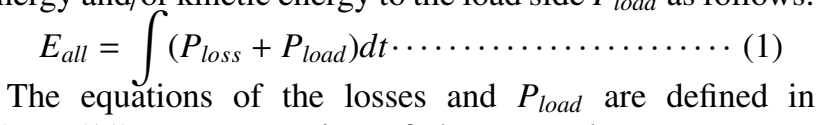
(2) to (11). $P_{\text {loss }}$ consists of the motor losses Loss $s_{\text {motor }}$ and inverter losses Loss inverter $_{\text {. Loss }}$ motor consist of copper losses Loss copper $_{\text {, iron losses Loss }}$ iron, and mechanical losses

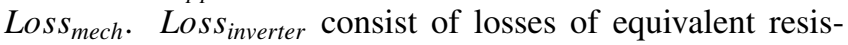
tance of FC Loss Lap $_{\text {, conduction losses Loss }}$ on and switching losses of switching devices $\operatorname{Loss}_{s w}$.

$$
\begin{aligned}
& P_{\text {loss }}=\text { Loss }_{\text {motor }}+\text { Loss }_{\text {inverter }} \\
& \text { Loss }_{\text {motor }}=\text { Loss }_{\text {copper }}+\text { Loss }_{\text {iron }}+\text { Loss }_{\text {mech }} \ldots \ldots \\
& \text { Loss }_{\text {inverter }}=\operatorname{Loss}_{\text {cap }}+\operatorname{Loss}_{\text {on }}+\operatorname{Loss}_{\text {sw }} \ldots \ldots \ldots \\
& \text { Loss }_{\text {copper }}=R_{m} i_{q}^{2} \ldots \ldots \ldots \ldots \ldots \ldots \ldots \ldots \ldots
\end{aligned}
$$

a) Correspondence to: Jongwon Heo. E-mail: jheo@ chiba-u.jp Chiba University

1-33, Yayoi-cho, Inage-ku, Chiba 263-8522, Japan

$$
\begin{aligned}
& \text { Loss }_{\text {iron }}=K_{I L} \omega^{3}\left(L_{q}^{2} i_{q}^{2}+\phi_{f}^{2}\right) \\
& \text { Loss }_{\text {mech }}=K_{m e} \omega^{2} \ldots \ldots \ldots \ldots \ldots \\
& \text { Loss }_{c a p}=V_{f c}^{2} / R_{d} \ldots \ldots \ldots \ldots \ldots \\
& \text { Loss }_{\text {on }}=K_{o n}\left|i_{q}\right| \ldots \ldots \ldots \ldots \ldots \\
& \text { Loss }_{s w}=K_{s w}\left|i_{q}\right| V_{f c} \ldots \ldots \ldots \ldots \\
& P_{\text {load }}=\tau_{L} \times \omega \ldots \ldots \ldots \ldots \ldots
\end{aligned}
$$

where $R_{m}$ is stator coil resistance, $i_{q}$ is q-axis current, $\omega$ is rotating speed, $L_{q}$ is q-axis inductance, $\phi_{f}$ is PM flux, $V_{f c}$ is voltage of FC, $R_{d}$ is equivalent parallel resistance of FC including discharge resistor, and $K_{I L}, K_{m e}, K_{o n}, K_{s w}$ are coefficients of each losses, respectively.

If $V_{q}$ can be approximated as $p \omega \phi_{f}$, where $p$ is number of pole pairs, (12) is obtained combined with the motion equation:

$$
C_{f c} V_{f c} \frac{d V_{f c}}{d t}+J_{m} \omega \frac{d \omega}{d t}+\omega \tau_{L}=0
$$

where $C_{f c}$ is capacitance of FC, and $J_{m}$ is inertial load.

\section{Maximum Continuous Operation Time Control}

In order to search the optimal time-FC voltage pattern $V_{f c}(t)$ which gives the longest continuous operation time, the calculus of variations is applied as the one of the optimization methods ${ }^{(2)}$. Overall energy loss $E$ from the time $t=0$ at the time of the power supply interruption until an arbitrary time $t=t_{a}$ is expressed as (13), if the loss power $P$ is expressed as (14).

$$
\begin{aligned}
E= & \int_{0}^{t_{a}} P d t \ldots \ldots \ldots \ldots \ldots \ldots \ldots \ldots \ldots \ldots \ldots \ldots \ldots \ldots \\
P= & R_{m} i_{q}^{2}+K_{I L}(p \omega)^{3}\left(\phi_{f}^{2}+L_{q}^{2} i_{q}^{2}\right)+K_{m e} \omega^{2}+V_{f c}^{2} / R_{d} \\
& +K_{o n}\left|i_{q}\right|+K_{s w}\left|i_{q}\right| V_{f c}+\tau_{L} \omega \ldots \ldots \ldots \ldots \ldots(14)
\end{aligned}
$$

Then, the Lagrange function $L$ can be obtained by (15) and (16).

$$
\begin{aligned}
& L\left(V_{f c}, \dot{V}_{f c}, t\right)=P\left(V_{f c}, \dot{V}_{f c}, t\right) \\
& \quad+\lambda\left(C_{f c} V_{f c} \frac{d V_{f c}}{d t}+J_{m} \omega \frac{d \omega}{d t}+\omega \tau_{L}\right) \cdots \cdots \\
& \frac{\partial L\left(V_{f c}, \dot{V}_{f c}, t\right)}{\partial V_{f c}}-\frac{d}{d t}\left(\frac{\partial L\left(V_{f c}, \dot{V}_{f c}, t\right)}{\partial \dot{V}_{f c}}\right)=0 \cdots \cdots
\end{aligned}
$$

where, $\lambda$ is Lagrangian multiplier.

$V_{f c}(t)$ which gives minimum loss energy in (13) can be generally obtained by solving (16). However the left side of (16) is always positive in any $V_{f c}(\mathrm{t})$ as shown in (17) in this case.

$$
2 V_{f c} / R_{d}+K_{s w}\left|i_{q}\right|>0
$$




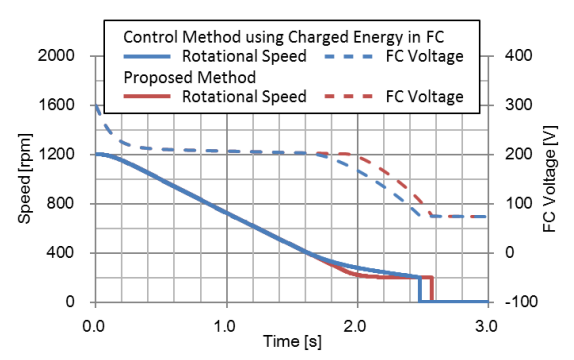

(a)

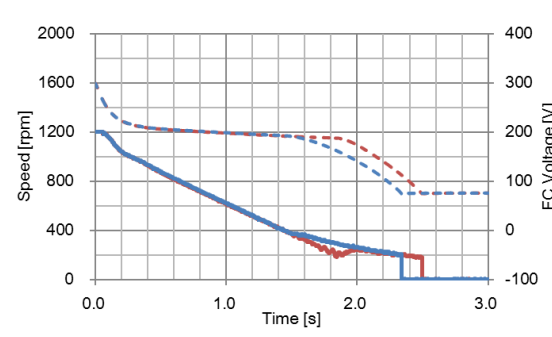

(b)

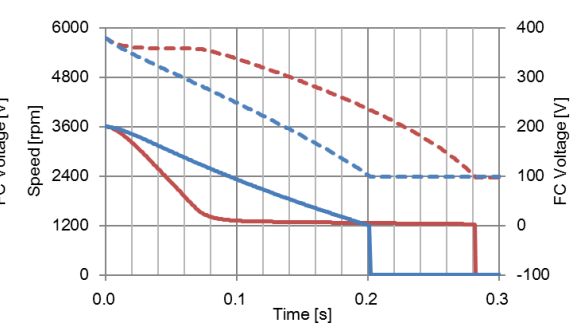

(c)

Fig. 1. Simulation and Experiment Results: (a) simulation results at the experiment conditions (Table 1), (b) experimental results, (c) simulation results at the compressor conditions (Table 2)

Therefore, the energy loss $E$ in (13) is monotonically increasing or decreasing with respect to the $V_{f c}(\mathrm{t})$, as far as $V_{f c}(\mathrm{t})>0$.

According to (12), $d \omega / d t$ is zero to keep the kinetic energy maximum. In this case $\omega(t)$ is $\omega_{0}$ which is given at $t=0$ and $V_{f c}(t)=\sqrt{ }\left(V_{f c 0}^{2}-2 \omega_{0} \tau_{L} / C_{f c} \cdot t\right)$. On the other hands, $V_{f c} / d t$ is zero to keep the capacitor energy maximum and the kinetic energy minimum. In this case $\omega(t)=\omega_{0}-\tau_{L} / J_{m} \cdot t$ according to $d \omega / d t=-\tau_{L} / J_{m}$ in (12) and $V_{f c}(t)$ is $V_{f c 0}$ which is given at $t=0$. If the energy losses at $\omega(t)=\omega_{0}$ and $\omega(t)=$ $\omega_{0}-\tau_{L} / J_{m} \cdot t$ are defined as $E\left(\omega_{0}\right)$ and $E\left(\omega_{0}-\tau_{L} / J_{m} \cdot t\right)$ respectively, $\Delta E=E\left(\omega_{0}\right)-E\left(\omega_{0}-\tau_{L} / J_{m} \cdot t\right)$ can be obtained as (18)

$$
\begin{aligned}
& \Delta E=\int_{0}^{t_{a}}\left[R_{m} i_{q 0}^{2}+K_{I L} \phi_{f}^{2}\left\{\omega_{0}^{3}-\left(\omega_{0}-\frac{\tau_{L}}{J_{m}} t\right)^{3}\right\}\right. \\
& +K_{I L} \omega_{0}^{3} L_{q}^{2} i_{q 0}^{2}+K_{m e}\left\{\omega_{0}^{2}-\left(\omega_{0}-\frac{\tau_{L}}{J_{m}} t\right)^{2}\right\} \\
& \left.+K_{o n}\left|i_{q 0}\right|+K_{s w}\left|i_{q 0}\right| \sqrt{V_{f c 0}^{2}-\frac{2 \omega_{0} \tau_{L}}{C_{f c}} t} t \frac{\tau_{L}^{2}}{J_{m}} t-\frac{2 \omega_{0} \tau_{L} t}{R_{d} C_{f c}}\right] d t \\
& =\int_{0}^{t_{a}}\left(A+\frac{\tau_{L}^{2}}{J_{m}} t-\frac{2 \omega_{0} \tau_{L} t}{R_{d} C_{f c}}\right) d t \ldots \ldots \ldots \ldots \ldots . . . \ldots \ldots
\end{aligned}
$$

where, $i_{q 0}$ is the q-axis current at the power interruption. Because $A$ is always positive value, $\Delta E$ can be expressed as follows:

$$
\Delta E>\int_{0}^{t_{a}}\left\{\tau_{L}\left(\frac{\tau_{L}}{J_{m}}-\frac{2 \omega_{0}}{R_{d} C_{f c}}\right) t\right\} d t=\int_{0}^{t_{a}}\left(\tau_{L} U t\right) d t
$$

In the compressor of residential air conditioner with $4.5 \mathrm{~kW}$ or less power, the inertial loads $J_{m}$ is at most about $0.001 \mathrm{kgm}^{2}$, the maximum $\omega_{0}$ is $733 \mathrm{rad} / \mathrm{s}(7000 \mathrm{rpm})$, the minimum $R_{d}$ is $20 \mathrm{k} \Omega$, and the minimum $C_{f c}$ is almost $1000 \mu \mathrm{F}$. Then, if the load torque $\tau_{L}$ is about $0.07 \mathrm{Nm}$ or more, the sign of $U$ is positive. In the compressor, from a load torque of $0.1 \mathrm{Nm}$ or more is generated due to the friction load, it could be said that $U$ is always positive. Therefore, the losses become the lowest when $\omega(t)$ is controlled as $\omega(t)=\omega_{0}-\tau_{L} / J_{m} \cdot t$.

After $\omega$ reaches the lower limit $\omega_{\min }$ which is set to avoid the damage to the compressor, $i_{q}$ is controlled as constant values to keep $\omega=\omega_{\min }$ until $V_{f c}$ reaches the lower limit $V_{f c m i n}$. According to (12), if $\omega$ is kept constant as $\omega_{\min }$, discharging power of FC is constant as shown in (20).

$$
C_{f c} V_{f c} \frac{d V_{f c}}{d t}=-\omega_{\min } \tau_{L}
$$

Thus, the higher $V_{f c}$ enables longer operation time after $\omega$
Table 1. Specifications and control parameters of the experiment.

\begin{tabular}{ccc}
\hline Symbol & Meaning & Value \\
\hline$\omega_{0}$ & Speed before Power interruption & $126 \mathrm{rad} / \mathrm{s}(1200 \mathrm{rmm})$ \\
$\omega_{\min }$ & Minimum Speed & $21 \mathrm{rad} / \mathrm{s}(200 \mathrm{rpm})$ \\
$\tau_{L}$ & Load Torque & $1.5 \mathrm{Nm}$ \\
$C_{f c}$ & Capacitance of FC & $1320 \mu \mathrm{F}$ \\
$J_{m}$ & Inertial Load & $0.028 \mathrm{kgm}^{2}$ \\
$V_{\mathrm{fco}}$ & DC Power supply voltage & $300 \mathrm{~V}$ \\
$V_{f c m i n}$ & Minimum FC voltage & $75 \mathrm{~V}$ \\
\hline
\end{tabular}

Table 2. Specifications and control parameters of the compressor.

\begin{tabular}{ccc}
\hline Symbol & Meaning & Value \\
\hline$\omega_{0}$ & Speed before Power interruption & $377 \mathrm{rad} / \mathrm{s}(3600 \mathrm{rpm})$ \\
$\omega_{\min }$ & Minimum Speed & $126 \mathrm{rad} / \mathrm{s}(1200 \mathrm{rpm})$ \\
$\tau_{L}$ & Load Torque & $2.0 \mathrm{Nm}$ \\
$C_{f c}$ & Capacitance of FC & $1020 \mu \mathrm{F}$ \\
$J_{m}$ & Inertial Load & $0.00075 \mathrm{kgm}^{2}$ \\
$V_{\mathrm{fco}}$ & DC Power supply voltage & $380 \mathrm{~V}$ \\
$V_{f c \min }$ & Minimum FC voltage & $100 \mathrm{~V}$ \\
\hline
\end{tabular}

reaches $\omega_{\min }$. For this sake, the proposed method to keep $V_{f c}$ constant instead $\omega$ is decelerate by load torque $\tau_{L}$ is reasonable for longer operation.

\section{Simulation and Experiment Results}

The same loss models in the previous section is utilized in the simulation. The power supply is interrupted at 0 second. The current reference is input through first-order lag filter in order to prevent sudden change in torque ${ }^{(1)}$.

The simulation results in Fig. 1(a) and the experimental results in Fig. 1(b), generally agree with each other. Thus, the simple loss model and power balance model in (12) are reasonable enough to propose the method. It is also revealed that the continuous operation time by proposed method is longer than the time of the control method using charged energy in FC. As shown in Fig. 1(c), assuming the smaller inertial load case such as Table 2, the continuous operation time by the proposed method is expected to be about $40 \%$ longer than the method using charged energy in FC.

\section{Conclusion}

The longest continuous operating pattern of $V_{f c}(t)$ at the power source interruption is derived theoretically by the simple loss models. The proposed method is verified by both the simulation and experimental test.

\section{References}

( 1 ) J. Heo, K. Matsuo, K. Natori, and K. Kondo: "Continuous Operation Control of PMSM with Compressor Loads of Air Conditioners in Case of DC Power Supply Loss", IEEJ Transactions on IA, Vol.137, No.9, pp.687-695 (2017) (in Japanese)

( 2 ) G.B. Arfken and H.J. Weber: "Mathematical Methods for Physicists, Fifth Edition”, Harcourt/Academic Press (2000) 